\title{
Abnormal Anatomical Etiology and the Resultant Bilateral Thoracic Outlet Syndrome
}

\author{
Jennifer L. Rizzo, EdD, ATC, CES \\ Concordia University Irvine
}

\begin{abstract}
The diagnosis of thoracic outlet syndrome (TOS) is challenging and primarily determined by clinical examination. Symptoms such as numbness and tingling in the arms when raised above the head make the rehabilitation process difficult due to the various manifestations of TOS presented to the athletic trainer (AT). An AT should understand the intricate anatomical characteristics of the thoracic outlet and how various TOS presentations may impact treatment. In this clinical commentary, I provide my own insights for understanding TOS from my perspective as a patient and AT. These insights are valuable when making diagnostic, therapeutic, and prognostic clinical decisions.
\end{abstract}

Keywords: arterial occlusion, neurological injury, Paget-Schroetter syndrome, thoracic nerve tension, upper cross syndrome, vascular thrombosis

Thoracic outlet syndrome (TOS) is a rare condition consisting of multiple symptoms and variants that typically presents with compression or impingement of the brachial plexus and/or the vasculature of the upper extremity. While this condition is considered to be relatively rare, ${ }^{1}$ its manifestations can result in substantial disability. Because it is such a rare condition, effective treatment strategies have not been consistently found within the evidence. The purpose of this clinical commentary is to provide a more robust appreciation of this condition from the perspective of a patient who is also an athletic trainer. Specifically, in this commentary, I discuss the etiologic considerations as well as the diagnostic, therapeutic, and prognostic considerations through the lens of my experiences as a patient.

Relevant anatomy in the etiology and diagnosis of TOS include the brachial plexus, the clavicle, the subclavicular/axillary artery, the scalenes, the pectoralis minor, and anatomical variants. Abnormal anatomical structures often include abnormal muscle attachments and/or hypertrophy, fibrous bands, and cervical ribs that generate compression of the brachial plexus. ${ }^{1-3}$ Impingement can also occur at the anterior shoulder through compression of the neurovascular bundle as it passes beneath the pectoralis minor muscle. ${ }^{3-6}$

Based on the anatomical structures involved, there are three known types of TOS: neurological thoracic outlet syndrome (NTOS), vascular thoracic outlet syndrome (VTOS), and arterial thoracic outlet syndrome (ATOS). According to the National Organization of Rare Disorders, ${ }^{1}$ 95\% of all TOS cases are NTOS. Accounts of VTOS may contribute approximately $4 \%$ of all cases and the last $1 \%$ of cases are ATOS compression. ${ }^{7-9}$ Compression that occurs only under the pectoralis minor is referred to as pectoralis minor syndrome (PMS). ${ }^{6,10}$

While variations in types of TOS may present differently in etiology and manifestation of symptoms, TOS as a general condition remains somewhat controversial, and is one of the most complicated syndromes of the upper extremity to treat. . $^{3,4,8,11,12}$

Rizzo (jennifer.rizzo@cui.edu) is with the College of Professional Studies, Concordia University Irvine, Irvine, CA, USA.
Furthermore, due to the complexity of surgical intervention and treatments, the process from diagnosis to rehabilitation is challenging. ${ }^{3,13,14}$ For the athletic trainer (AT), TOS presents challenges specifically because of the AT's diagnostic role, addressing symptoms, and the oversight of the rehabilitation process. The diversity of symptoms can also draw ATs into a web of symptom management that may, unfortunately, render them unable to find the underlying source of the problem.

The most challenging variant of TOS to diagnose has been reported to be NTOS because of the ambiguity of symptoms. ${ }^{4,8,15}$ Typical presentation includes pain in the neck, shoulders, and arms. Pain may also present in the face and head. Thenar and hypothenar eminence atrophy, and numbness and/or tingling in the arm and hand may be present. Symptoms are often increased when the arms are overhead. . $^{3,411,16}$ Paget-Schroetter disease, which is synonymous with VTOS, presents as swelling in the arm and hand, discoloration and feeling of fullness, or aching in the arm. ${ }^{7-9}$ Coldness, numbness, tingling, pain, white discoloration in the hand, and cramping of the forearm and hand with activity have been reported to occur more prevalently with ATOS. ${ }^{3-5}$ In addition, pain is felt in the hands and arms but not typically in the neck or shoulder. Both VTOS and ATOS have visible symptoms in the arm making the diagnostic process easier. Treatment of VTOS and ATOS with first rib removal and decompression has been recommended to be completed as soon as possible due to potentially limb-threatening complications if there is no treatment. ${ }^{3-5}$

The diagnosis of TOS is often based on observation of known clinical symptoms and exclusion of other conditions. The small number of TOS patients and even fewer specialists treating TOS often necessitates multidisciplinary evaluation. ${ }^{3-5}$ TOS diagnosis is inconsistent and there are no gold standard assessment practices (Table 1). Urbenek et al. ${ }^{17}$ reported that at least $26 \%$ of asymptomatic patients at the Medical University of Silesia tested positive on at least one TOS diagnostic test. In addition, many people that exhibit symptoms often experience them so infrequently that medical attention is not often sought. The inconsistency of testing and the variety of symptoms makes diagnosis for ATs difficult. Yet, ATs typically see their patients daily and are better able to observe symptom presentation and changes. Thus, the importance 
of AT referral of an athlete to aggressively seek preemptive specialist evaluation may expedite treatment initiation and rehabilitation, thereby increasing the rate of success.

Table 2 outlines typical TOS treatments and surgery. Experts on TOS have suggested that surgical intervention should only be considered for NTOS when all treatments have failed. ${ }^{13,15,18}$ As previously mentioned, surgery for ATOS and VTOS are required to restore blood flow through the vein and artery. ${ }^{19,20}$ Decompression surgery, scalenectomy, involves removing the anterior and middle scalene and first rib. ${ }^{15,20}$ If a patient reports with a cervical rib, as observed on the radiograph, the entire cervical rib is suggested to be removed. ${ }^{21}$
Nonsurgical treatments or less invasive options should be attempted prior to discussing surgery for NTOS. ${ }^{13,22,23}$ Rehabilitation efforts may help the patient understand that changes in how they move during activities of daily living (ADLs) will lessen the risk for placing his or her arms in positions that will exacerbate the symptoms of TOS. Flexibility and mobility exercises assist with posture corrections and should be included in rehabilitation. ${ }^{13}$ Nonconventional treatments that may help relieve symptoms include: cupping, acupuncture, and chiropractic care. These treatments alone may not be enough to alleviate symptoms, but when combined during the rehabilitation process may provide a treatment combination for greater success in the reduction of pain.

\section{Table 1 Thoracic Outlet Syndrome (TOS) Procedures and Practices}

\begin{tabular}{|c|c|c|}
\hline Diagnostic Tools & Procedure & Diagnosis/Results \\
\hline $\begin{array}{l}\text { Disabilities of the Arm, } \\
\text { Shoulder, and Hand (DASH) } \\
\text { Score }\end{array}$ & 30-question survey of pain and functionality & $\begin{array}{l}\text { Determines activities of daily living, social and } \\
\text { psychological functioning }\end{array}$ \\
\hline $\begin{array}{l}\text { Magnetic resonance imaging } \\
\text { (MRI) } \\
\text { Magnetic resonance } \\
\text { angiography (MRA) }\end{array}$ & MRI offers detailed cross-sectional image of structures & $\begin{array}{l}\text { Rule out disorders such as shoulder injuries and } \\
\text { cervical spine injuries }\end{array}$ \\
\hline Radiography & $\begin{array}{l}\text { Imaging of bony structures of the cervical, thoracic, and shoulder } \\
\text { region }\end{array}$ & $\begin{array}{l}\text { Cervical ribs and other bony malformations that } \\
\text { may cause compression of brachial plexus }\end{array}$ \\
\hline Electromyography (EMG) & $\begin{array}{l}\text { Tests the electrical activity of the cervical and shoulder } \\
\text { musculature }\end{array}$ & $\begin{array}{l}\text { Location of nerve compression and muscle atrophy } \\
\text { due to neurological damage }\end{array}$ \\
\hline $\begin{array}{l}\text { Scalene and pectoralis } \\
\text { muscle block }\end{array}$ & $\begin{array}{l}\text { Lidocaine is injected into the muscle belly; temporary relief of } \\
\text { symptoms is a sign that scalenectomy surgery may be effective }\end{array}$ & $\begin{array}{l}\text { Many TOS surgeons consider the most effective for } \\
\text { neurological thoracic outlet syndrome diagnosis }\end{array}$ \\
\hline Arteriography & $\begin{array}{l}\text { Determines narrowing of an artery and can diagnose arterial } \\
\text { thoracic outlet syndrome (ATOS) }\end{array}$ & ATOS: If blockage, surgery will be warranted \\
\hline $\begin{array}{l}\text { Doppler or duplex } \\
\text { examinations }\end{array}$ & $\begin{array}{l}\text { Injecting dye into the vein to diagnose vascular thoracic outlet } \\
\text { syndrome (VTOS) }\end{array}$ & VTOS: If blockage, surgery will be warranted \\
\hline Clinical special tests & $\begin{array}{l}\text { Upper limb tension test, Adson's, Allen's, military brace test, } \\
\text { Roos Test }\end{array}$ & Test are inconclusive and may have false positive \\
\hline
\end{tabular}

Table 2 Types of Thoracic Outlet Compression

\begin{tabular}{|c|c|c|c|c|c|}
\hline Syndrome & $\begin{array}{l}\text { Signs and } \\
\text { Symptoms }\end{array}$ & Causes & $\begin{array}{l}\text { Diagnostic } \\
\text { Procedures }\end{array}$ & $\begin{array}{l}\text { Differential } \\
\text { Diagnosis }\end{array}$ & Treatment \\
\hline $\begin{array}{l}\text { Neurogenic } \\
\text { thoracic } \\
\text { outlet } \\
\text { syndrome }\end{array}$ & $\begin{array}{l}\text { Numbness and tingling } \\
\text { in the arm or hand, pain } \\
\text { in the scapula area, } \\
\text { medial elbow, wrist, and } \\
\text { hand. Weakness and } \\
\text { atrophy in the hand. }\end{array}$ & $\begin{array}{l}\text { Trauma to the neck, compression } \\
\text { or distraction of the brachial } \\
\text { plexus as it leaves the intersca- } \\
\text { lene triangle }\end{array}$ & $\begin{array}{l}\text { Disabilities of the Arm, } \\
\text { Shoulder, and Hand } \\
\text { (DASH) survey, scalene } \\
\text { block injection, electro- } \\
\text { myography, radiographs } \\
\text { Special test: Adson's } \\
\text { test, Allen's test, military } \\
\text { brace test, upper limb } \\
\text { tension test, and Roos } \\
\text { Test }\end{array}$ & $\begin{array}{l}\text { Rotator cuff tear, } \\
\text { cervical disc dis- } \\
\text { ease, pectoralis } \\
\text { minor syndrome }\end{array}$ & $\begin{array}{l}\text { Nonsurgical: physi- } \\
\text { cal therapy, posture } \\
\text { correction, occupa- } \\
\text { tional changes } \\
\text { Surgical decompres- } \\
\text { sion: first rib removal, } \\
\text { scalenectomy }\end{array}$ \\
\hline $\begin{array}{l}\text { Arterial tho- } \\
\text { racic outlet } \\
\text { syndrome }\end{array}$ & $\begin{array}{l}\text { Hand is cool and pale, } \\
\text { pulse in wrist is weak or } \\
\text { diminished. }\end{array}$ & $\begin{array}{l}\text { Compression of the artery as it } \\
\text { passes under the clavicle, usually } \\
\text { caused by variations of anatomy }\end{array}$ & $\begin{array}{l}\text { Pulse-volume readings, } \\
\text { arteriography }\end{array}$ & & $\begin{array}{l}\text { Decompression sur- } \\
\text { gery and repair the } \\
\text { damaged artery }\end{array}$ \\
\hline $\begin{array}{l}\text { Venous tho- } \\
\text { racic outlet } \\
\text { syndrome }\end{array}$ & $\begin{array}{l}\text { Swelling of the entire } \\
\text { arm and hand. Veins } \\
\text { may be prominent, } \\
\text { discoloration of the arm } \\
\text { may or may not be } \\
\text { present. }\end{array}$ & $\begin{array}{l}\text { Compression due to cervical rib } \\
\text { or abnormal fist rib }\end{array}$ & $\begin{array}{l}\text { Doppler test and } \\
\text { venography }\end{array}$ & & $\begin{array}{l}\text { Decompression sur- } \\
\text { gery, anticoagulant } \\
\text { drugs, repair vein as } \\
\text { needed }\end{array}$ \\
\hline
\end{tabular}




\section{My Case Presentation}

Throughout my life, I have been an overhead athlete, playing over a decade of competitive volleyball. When my college career ended, I started training for triathlons. My symptoms related to TOS began when I was 32 years old, working as an AT and associate professor at a small university. I was a mesomorph with forward head posture and bilateral arm, hand, and neck muscle tone symmetry. Prior to TOS symptom onset, I sought rehabilitation for chronic shoulder pain and instability associated with a superior labral tear from anterior to posterior (SLAP) lesion, chronic grade 2 supraspinatus and subscapularis strains, and chronic infraspinatus muscle atrophy. Having played volleyball through college, I was used to having a sore shoulder. During a physical therapy session while performing wall slides with elastic band resistance, a tremor presented in my right hand. The tremor was the first TOS symptom to present. It was an activation tremor when my hand was supinated. At first the tremor was thought to be due to fatigue while doing shoulder rehab. The tremor started to get worse and I would experience it when gripping, writing or any time my arm was above $100^{\circ}$ flexion. When the pain started, it was a stabbing pain near my scapula on the right side. The pain was so severe I could not lay down or put on my clothes; even breathing was difficult. I sought out care from a chiropractor over the course of 3 years, but the cervical adjustments I received did not help the pain. As my pain increased, so did the tremor. Physical therapy made the symptoms worse and I finally stopped going because most sessions resulted with my arm in a sling.

My symptoms quickly progressed from pain in the upper trapezius to "zapping" (like a lightning bolt) pain down the arm. Pain presented in my first and fifth digit. In hind sight, I had experienced pain in my hands for many years prior but I did not associate the symptoms as anything more than early onset arthritis from doing manual therapy. I would experience pain in my thumb especially during the athletic seasons when I did significantly more manual therapy interventions.

When pain increased, my daily activities were substantially affected. I have always been right handed but during the process of getting diagnosed I lost function of my right hand. I would frequently drop things; my grip was weak and my arm would fatigue almost instantly when used. I started to use my left arm for everything. As a result, pain started to present in my left arm around the scapula. However, the pain never traveled to my hand like it did on the right side, but the scapula pain would prevent me from sleeping or getting comfortable. I experienced a feeling of heaviness in my right forearm and hand that had an unpredictable onset during the day, but was felt with almost every workout. Along with the heaviness, I frequently dropped objects and had difficulty opening jars and lids-things I never had trouble with a couple years prior. I woke up multiple times during the night with one or both of my hands completely numb.

The difference between my symptoms in my right and left arms was dramatic. The right arm had a tremor with pain that zapped into the hand. I also experienced weakness and fatigue in my right arm. My left arm was painful in the scapula region that increased when stretching the trapezius and rhomboids. I had been experiencing a "cloudy" sensation in my right ear with facial and dental pain on both sides, but the right was significantly more intense.

\section{Differential Diagnosis}

My diagnosis of TOS was a diagnosis of exclusion and my symptoms on both the right and left side presented very differently, resulting in multiple tests needed to rule out different conditions. When the TOS symptoms presented during physical therapy the process of ruling out differential diagnoses started with a cervical spine magnetic resonance image (MRI) and radiographs. See Table 3 for a complete list of all differential diagnoses ruled out and what testing was performed to determine the exclusion of the disease.

During all the testing, I sought alternative therapies from multiple chiropractors, physical therapists, and acupuncturists. I also pursued treatment from a naturopath who tested for food allergies and sensitives that may have been causing high inflammation in my system. Through this exploratory process, I was put on multiple supplements and tried elimination diets to decrease inflammation. While my overall health improved, my tremor did not change and my pain in my arms persisted.

\section{My Course of Interventions}

Over the course of many years, I treated my symptoms through physical therapy, chiropractic care, acupuncture, and self-treatment on the foam roller and lacrosse ball. Acupuncture is what I preferred to manage my symptoms. To compensate for my right arm dysfunction, I learned to use my left hand for many of my daily responsibilities. I adapted so well, in fact, that I often wrote left handed on the whiteboard when I could not flex or abduct my right shoulder to $90^{\circ}$. I found that rehabilitation exacerbated my symptoms; the pain was so intense I would only find relief through immobilization. Chiropractic care (specifically a first rib adjustment) provided minimal symptom relief for up to 2-3 days, helping to reduce the pain I experienced in my upper trapezius. Despite all the treatments, my function had deteriorated. I was unable to engage in meaningful activities so I needed to seek out a new TOS intervention strategy-surgery.

See Table 3 for the referral process to a variety of specialists that eventually led me to a vascular surgeon. The vascular surgeon performed a right side first rib removal (FRR). The decision to do FRR was based on clinical examination of symptoms, results of scalene injections, and MRI. The vascular surgeon performed right thoracic outlet decompression, subtotal resection of the subclavius, anterior and middle scalenes, and total resection of scalene minimus. Division of the pectoralis minor, brachial plexus neurolysis, and subclavian artery lysis was also completed. The surgeon reported the anterior and middle scalenes as being twice their normal size, narrowly attached on the first rib which compressed the artery and the brachial plexus (Figure 1). A scalene minimus muscle traversing C7-C8 interspace attached to the Sibson's fascia and wrapped around the subclavian artery. The surgeon removed the first rib to ensure that rib fragments did not cause future issues or the scalenes did not reattach to the rib as this was the most likely strategy to decrease future complications.

When I woke up from FRR surgery on the right side I immediately noticed that my facial pain was gone and my hearing on the right side had improved. The pain in my right arm had masked some of the facial pain I had been feeling. The facial pain on the left side was not as severe and postsurgery the decrease in symptoms was not as noticeable as the right side. While this improved my symptoms in the short term, the effectiveness of this treatment did not last. After about 6 months, the pain on the right side started to increase again.

I chose the same vascular surgeon that performed the right side FRR to perform the same thoracic outlet decompression procedure 
Table 3 Timeline of Medical Procedures and Treatments

\begin{tabular}{llll}
\hline Date & $\begin{array}{l}\text { Medical } \\
\text { Professional }\end{array}$ & $\begin{array}{l}\text { Diagnostic } \\
\text { Procedures }\end{array}$ & Results/Notes \\
\hline $12 / 2013$ & & & $\begin{array}{l}\text { Initial pain in right shoulder presented after lifting up a stack of paper } \\
\text { at } 90^{\circ} \text { shoulder flexion. }\end{array}$
\end{tabular}

symptoms

$12 / 9 / 2013$

Orthopedic surgeon \#1

12/2013-2/2014 Physical therapy

Right shoulder radiograph Right shoulder MRI

Rehab for shoulder stability

Spring $2014 \quad$ Chiropractor, acupuncturist, massage therapist

Spring $2014 \quad$ Naturopathic MD

5/7/2014 Orthopedic surgeon \#2

5/28/2014 Neurologist \#1

$5 / 24 / 2014$

$6 / 8 / 2014$

$7 / 20 / 2016$

$10 / 31 / 2016$

$8 / 16 / 2016$

$11 / 9 / 2016$

$11 / 15 / 2016$

9/26/2016

$12 / 29 / 2016$

$1 / 17 / 2017$

$6 / 29 / 2017$

Pain management doctor \#3

Right and left brachial

plexus MRI

EMG study cular surgeon \#1

No new imaging alis minor injection

Brain MRI

Right first rib removal and pectoralis minor release surgery

Physical therapy injection
Labrum tear, supraspinatus and subscapularis tear, complete atrophy of infraspinatus. I was prescribed physical therapy for my shoulder, shoulder surgery not warranted.

A tremor presented during physical therapy along with pain 8/10 in upper trapezius. Physical therapy increased stability of the right shoulder and original shoulder pain decreased. Physical therapy was discontinued after resolution of shoulder symptoms, despite continued tremor.

No diagnostic imaging performed I self-referred for alternative treatment because physical therapy was not helping with neurological symptoms. I continued treatment for years due to temporary decreases in pain.

Found no severe allergies but sensitive to some foods. Systematic inflammation was seen in the A1C levels. Naturopath recommended to reduce inflammation via diet and supplements. I did not have resolution of symptoms but felt the best I had in months. I was able to train for a 70.3 triathlon.

Cervical radiography and MRI

Suspects TOS and referred to vas-

No compression of the nerve root in the cervical spine MRI or radiographs.

The EMG confirmed tear of suprascapular nerve at the suprascapular notch with complete infraspinatus muscle atrophy. The injury appears to be old and nothing can be done to fix the atrophied muscle.

This orthopedic doctor suspected TOS, he did not believe surgery was an option but referred me to a vascular surgeon for diagnosis.

The vascular surgeon did not do any additional diagnostic testing. He confirmed a TOS diagnosis based on symptoms and previous imaging. He recommended continuing physical therapy.

Confirmed diagnosis of TOS, recommended surgery. First rib removal (FRR) and pectoralis minor release (PMR).

rior and middle scalene and pectr

Reviewed current documents

I made an appointment to see neurologist \#2 for another opinion on treatment options. Confirmed TOS, referred back to vascular surgeon \#2.

I found my own pain management doctor to do the scalene injection to avoid a 2-hr drive to see the doctor the surgeon recommended. This test was inconclusive due to physician error during the injection.

Saw the pain management doctor that the surgeon recommended for the injections. Positive TOS.

Positive pectoralis minor syndrome

Right pectoralis minor block
Negative multiple sclerosis or other brain lesion diseases.

Surgery revealed anterior and middle scalene muscles hypertrophied two times the normal size. Also, attachment on the first rib was narrower than normal, causing compression of the neurovascular structures.

The goals of physical therapy were to increase strength, cervical and shoulder range of motion, and scar tissue management. After months of physical therapy, pain was starting to increase and I discontinued physical therapy.

Symptoms appeared on the left arm and started to reappear on the right arm. The vascular surgeon ordered another round of scalene and pectoralis minor release injections following an MRI. MRI showed significant scar tissue on right, left appears to have no compression.

Vascular surgeon \#2 does not believe the pec minor is causing the new presentation of symptoms. 
Table 3 (continued)

\begin{tabular}{|c|c|c|c|}
\hline Date & $\begin{array}{l}\text { Medical } \\
\text { Professional }\end{array}$ & $\begin{array}{l}\text { Diagnostic } \\
\text { Procedures }\end{array}$ & Results/Notes \\
\hline $8 / 10 / 2017$ & $\begin{array}{l}\text { Pain management } \\
\text { doctor \#3 }\end{array}$ & Left anterior scalene block injection & Vascular \#2 confirms TOS on left side and recommends surgery. \\
\hline $8 / 24 / 2017$ & $\begin{array}{l}\text { Pain management } \\
\text { doctor \#3 }\end{array}$ & $\begin{array}{l}\text { Right anterior scalene block } \\
\text { injection }\end{array}$ & $\begin{array}{l}\text { Right side scalene block suggests that scalene muscles reattached and } \\
\text { are causing compression of the neurovascular symptoms again. }\end{array}$ \\
\hline $12 / 16 / 2017$ & Vascular surgeon $\# 2$ & Left first rib removal surgery & $\begin{array}{l}\text { The anterior and middle scalene are hypertrophied } 2 \times \text { the normal size } \\
\text { with very narrow attachment. The neurovascular structures were } \\
\text { compressed with an anterior and posterior deviation. The subclavian } \\
\text { artery grew a branch to bypass the compression hence why minimal } \\
\text { vascular symptoms and no blood clot developed. }\end{array}$ \\
\hline Spring 2018 & Physical therapy & & Increase strength, work on scar tissue, increase range of motion. \\
\hline $3 / 1 / 2018$ & Vascular surgeon \#2 & $\begin{array}{l}\text { Right anterior and middle } \\
\text { scalenectomy }\end{array}$ & $\begin{array}{l}\text { The anterior scalene attached and wrapped around the neurovascular } \\
\text { structures in addition to scar tissue around the initial incision. The } \\
\text { anterior scalene was removed from the neurovascular structure and } \\
\text { scar tissue removed. }\end{array}$ \\
\hline $3 / 3 / 2018$ & Vascular surgeon \#2 & Chest radiograph & $\begin{array}{l}\text { Elevation of right diaphragm and difficulty breathing. Diagnosis of } \\
\text { possible paralyzed diaphragm. }\end{array}$ \\
\hline $6 / 12 / 2018$ & Thoracic surgeon & No new imaging & $\begin{array}{l}\text { Based on the postoperative chest radiograph recommended surgery } \\
\text { to tac diaphragm. Atelectasis in the bottom lobe seen on radiograph, } \\
\text { due to not filling the lung. Referred to pulmonologist for second } \\
\text { opinion. }\end{array}$ \\
\hline $6 / 13 / 2018$ & Pulmonologist & $\begin{array}{l}\text { Sniff test, chest CT scan, pulmonary } \\
\text { function tests }\end{array}$ & $\begin{array}{l}\text { Right diaphragm paralysis, wait to see if phrenic nerve regenerates on } \\
\text { own. Advises against recommended surgery from thoracic surgeon. }\end{array}$ \\
\hline $12 / 21 / 2018$ & Pulmonologist & CT scan, sniff test & $\begin{array}{l}\text { May have slight movement posterior-lateral diaphragm but nothing } \\
\text { significant. Atelectasis in lungs cleared. No follow-up needed- } \\
\text { paralyzed diaphragm. }\end{array}$ \\
\hline
\end{tabular}

Abbreviations: $\mathrm{CT}=$ computed tomography; $\mathrm{EMG}=$ electromyography; $\mathrm{MD}=$ medical doctor; $\mathrm{MRI}=$ magnetic resonance imaging; $\mathrm{TOS}=$ thoracic outlet syndrome .

on the left, with no pectoralis minor division. Based on my symptoms, the surgeon did not think that the pectoralis minor was causing compression and chose not to perform the pectoralis minor release. During surgery, the surgeon found the left anterior and middle scalenes were hypertrophied to double their size, similar to the right. The left anterior scalene posteriorly deviated the brachial plexus and subclavian artery, while the middle scalene deviated the brachial plexus and subclavian artery anteriorly. A nonunion fracture of the first rib at the costochondral junction that had not healed was also discovered during surgery. Pseudarthrosis occurred due to the mobility at the fracture location (Figure 1). Additionally, the subclavian artery had generated an additional branch above the compression which was clipped and cauterized during surgery to allow for the subclavius muscle to be dissected from the first rib. The reason I did not have arterial symptoms on the left was due to this arterial branch that was supplying blood flow to the left arm.

After the left FRR surgery, the right side had returned to all the presurgery symptoms. A new symptom had also developed and I felt like someone was squeezing my neck and causing decrease blood flow to my brain. I saw the surgeon again and he recommended another surgery to remove scar tissue. The anterior scalene muscle reattached to the brachial plexus and was impinging the neurological and vascular structures. He removed the anterior and middle scalene and cleaned out any scar tissue that had formed.

\section{My Outcomes}

The outcomes of surgery were different between my right and left arms. The left side surgery resulted in decreased pain and increased function. The left side was considered a success. The right side had most of the symptoms return. The first notable symptom was right side blood pressure asymmetry of $152 / 88$ compared to my left arm of 121/78. The right arm occasionally felt heavy and became slightly darker in color than the left hand. Blood pressure variations are found in the literature when referring to VTOS and ATOS. ${ }^{7-9}$ Within a couple months following right FRR, my primary complaint was that my "hand did not work". On "bad" days my grip strength was about $50 \%$ of the left hand, and wrist flexion and extension range of motion (ROM) was deficient. On "good" days, full wrist ROM was maintained. Greening et $\mathrm{al}^{24}$ states that proximal nerve tension can cause decreased function and ROM. No other literature was found to discuss wrist pain and dysfunction associated with TOS; only with carpal tunnel syndrome. ${ }^{24-26}$ Based on the outcomes of my first surgery on my right side, a full scalenectomy of the right anterior/middle scalene and scar tissue removal was recommended (Figure 2). As a result of the full scalenectomy on the right side I experienced complications, potentially due to damage of the phrenic nerve during surgery, which resulted in a paralyzed right diaphragm (Figure 3). Common complications reported in the literature also include injury to the long thoracic nerve during surgery. ${ }^{25}$ Paralyzed diaphragm was not discussed in the literature as a complication of first rib removal.

Recovery was much more difficult mentally and physically than I can put into words. Nerves were regenerating and nerves irritated in surgery were trying to heal. After the right FRR, my arm pit felt like a thousand bees stinging any time clothing touched it. I slept on the couch propped up for 6 weeks unable to lay flat in any position. Recovery from surgery was not linear, pain fluctuated daily and seemed unpredictable. The left side FRR was a much 


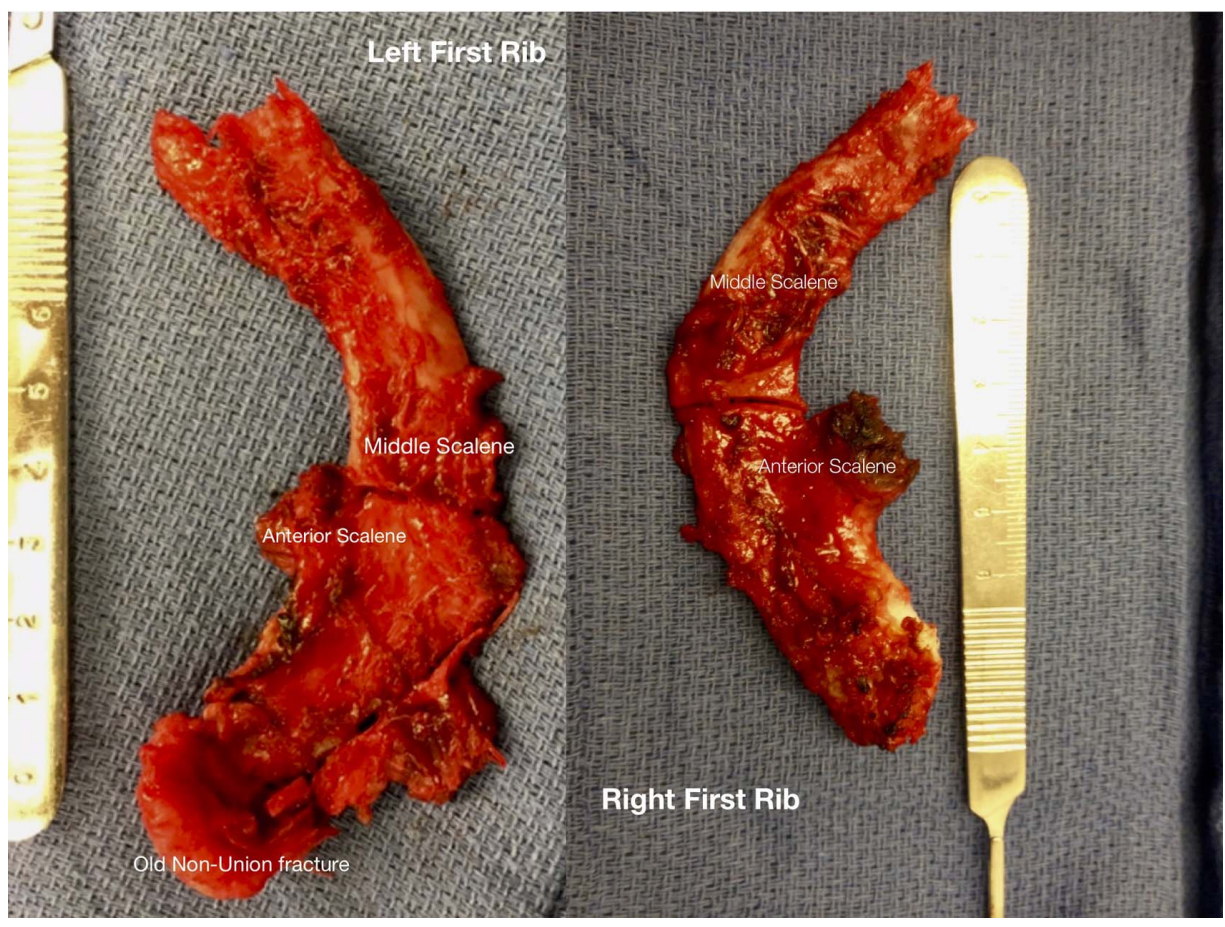

Figure 1 - First ribs removed during surgery.

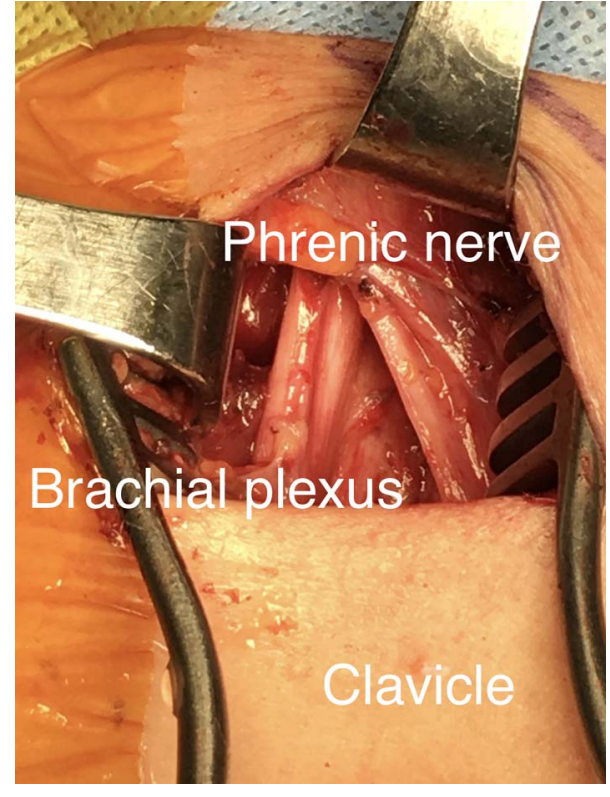

Figure 2 - Brachial plexus of patient-March 1, 2018.

smoother recovery. I was able to lie down by the fourth week. The pain was managed much better and I only needed prescription pain medication for 1 week.

After the third surgery, the right scalenectomy, pain management was the easiest. Unfortunately, the scalenectomy resulted in a paralyzed diaphragm. Breathing was difficult and walking four steps resulted in breathlessness. When rolling over in bed I had to sit up to catch my breath. I ended up with pneumonia a couple weeks after surgery. The problem with pneumonia is that

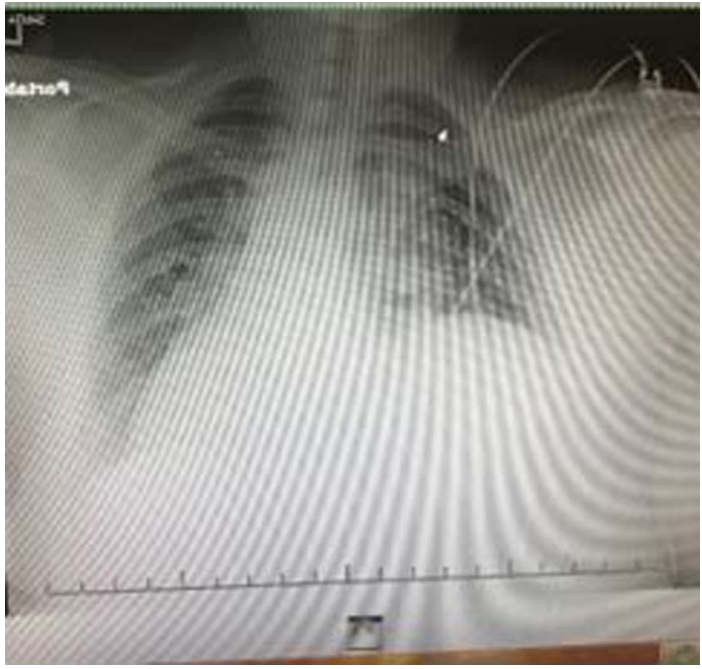

Figure 3 - Elevated right diaphragm post scalenectomy surgery.

postoperative pain is excruciating when coughing. Deep breaths and coughing assist in moving fluids out of the lungs, both of which I had difficulty due to postoperative pain.

\section{Insights From My Experiences as a Patient With TOS}

I struggled with a complex case of NTOS with symptoms of VTOS. This condition has impacted my ability to perform at work, maintain my level of fitness, and negatively influenced my sense of self. Overall, following the three surgeries the pain has 
decreased. I am able to use both hands even though they fatigue easily and go numb when I raise my hands above my head. I am able to work as an AT, but the paralysis of my right diaphragm has not resolved and continues affect my level of fitness.

Due to the rarity of TOS there is minimal literature on the outcomes associated with surgical management. In a study of 170 patients who underwent TOS surgery, Axelrod et al. found at long-term follow-up (approximately 4 years), $18 \%$ of patients were disabled. ${ }^{19}$ Interestingly, Al-Hashel reported that patients who underwent surgical intervention within 3 months of symptoms had significantly better results with less permanent nerve issues than the group that underwent 6 months of physical therapy prior to surgery. ${ }^{1}$ I exhausted all resources prior to surgical intervention on the right side, totaling more than 3 years of symptoms prior to FFR. On the left side, I had surgery within 6 months from when symptoms presented; my surgical outcomes were better on the left than the right side. Due to the amount of disability in my right arm, I chose not to pursue physical therapy on the left arm. Despite Al-Hashel's recommendation for immediate surgery, due to the clinical difficulty of diagnosing NTOS, the intensity of surgery, and the risk of complications, I believe that physical therapy should be attempted prior to surgery. Choosing a nonoperative approach is important, but there needs to be recognition when physical therapy is no longer improving patient symptoms and surgery is required. The literature does not provide a physical therapy to surgery timeline and should be researched in the future to improve patient outcomes.

Another major contributing factor to poor outcomes is psychosocial well-being. Those with depression have been reported to be 15 times more likely to have prolonged disability after surgery than those without depression. ${ }^{19}$ From my own experiences, I was disheartened through the referral and rehabilitation process, especially prior to undergoing surgery. Interestingly, I would not have considered myself "depressed", but wonder if my psychosocial health was a contributing factor to my outcomes. From what I have learned, this evidence matches up well with what I have experienced. Patients in Axelrod's study presented with the psychosocial variable of depression. Patients with TOS were compared to patients with chronic low back pain or fibromyalgia. ${ }^{19}$ Because the diagnosis and referral process is complex, psychosocial health is critically important to consider as intervention strategies are explored.

\section{Clinical Bottom Line}

My case of TOS is a complicated case that breaks down how diagnosis, treatment, and rehabilitation can be very different between patients. Each patient with TOS is unique and may offer very different presentations. As an AT I have the added value to witnessing a complex case from the perspective of a patient. The intricacy and overlap of symptoms make NTOS diagnosis difficult; early recognition and referral may be the difference in successful patient outcomes. As seen in the literature, patients that immediately sought treatment had better outcomes than those with chronic symptoms. Starting rehabilitation for TOS early, while the patient is seeking a diagnosis of exclusion, may provide better results. Lastly, psychosocial factors, especially depression, play a key role in predicting the perceived disability after surgery. Considering a patient's psychosocial well-being may lead to successful treatment of NTOS.

\section{References}

1. Mackinnon S. Thoracic outlet syndrome. Ann Thorac Surg. 1994;58(2):287-289. PubMed ID: 8067821 doi:10.1016/00034975(94)92194-6

2. Peek J, Vos C, Ünlü Ç, Schreve M, Van de Mortel R, De Vries JP. Long-term functional outcome of surgical treatment for thoracic outlet syndrome. Diagnostics. 2018;8(1):7. doi:10.3390/diagnostics8010007

3. Freischlag J, Orion K. Understanding thoracic outlet syndrome. Scientifica. 2014;2014:248163. PubMed ID: 25140278 doi:10. $1155 / 2014 / 248163$

4. Sanders RJ, Hammond SL, Rao NM. Diagnosis of thoracic outlet syndrome. J Vasc Surg. 2007;46(3):601-604. PubMed ID: 17826254 doi:10.1016/j.jvs.2007.04.050

5. Ferrante MA. The thoracic outlet syndromes. Muscle Nerve. 2012;45(6):780-795. doi:10.1002/mus.23235

6. Sanders RJ, Annest SJ. Thoracic outlet and pectoralis minor syndromes. Semin Vasc Surg. 2014;27(2):86-117. doi:10.1053/j.semvascsurg. 2015.02.001

7. Hussain MA, Aljabri B, Al-Omran M. Vascular thoracic outlet syndrome. Semin Thorac Cardiovasc Surg. 2016;28(1):151-157. doi:10.1053/j.semtcvs.2015.10.008

8. Klaassen Z, Sorenson E, Tubbs RS, et al. Thoracic outlet syndrome: a neurological and vascular disorder. Clin Anat. 2014;27(5):724-732. PubMed ID: 23716186 doi: 10.1002/ca.22271

9. Sanders RJ, Hammond SL. Venous thoracic outlet syndrome. Hand Clin. 2004;20(1):113-118. PubMed ID: 15005393 doi:10.1016/ S0749-0712(03)00094-5

10. Sanders RJ, Annest SJ. Pectoralis minor syndrome: subclavicular brachial plexus compression. Diagnostics. 2017;7(3):46. doi:10. 3390/diagnostics7030046

11. Singh D, Pingala RK, Reddy LRC, Vani S. Thoracic outlet syndrome: presentation and management. Indian J Surg. 2006;68(2):93-96.

12. Sanders RJ, Hammond SL, Rao NM. Thoracic outlet syndrome: a review. Neurologist. 2008;14(6):365-73. PubMed ID: 19008742 doi:10.1097/NRL.0b013e318176b98d

13. Kuwayama DP, Lund JR, Brantigan CO, Glebova NO. Choosing surgery for neurogenic TOS: the roles of physical exam, physical therapy, and imaging. Diagnostics. 2017;7(2):37. doi:10.3390/ diagnostics 7020037

14. Hixson KM, Horris HB, McLeod TCV, Bacon CEW. The diagnostic accuracy of clinical diagnostic tests for thoracic outlet syndrome. J Sport Rehabil. 2017;26(5):459-465. PubMed ID: 27632823 doi:10. 1123/jsr.2016-0051

15. Al-Hashel JY, El Shorbgy AA, Ahmed SF, Elshereef RR. Early versus late surgical treatment for neurogenic thoracic outlet syndrome. ISRN Neurol. 2013;2013:673020. PubMed ID: 24109518 doi:10.1155/2013/673020

16. Abdul-Jabar H, Rashid A, Lam F. Thoracic outlet syndrome. Orthop Trauma. 2009;23(1):69-73. doi:10.1016/j.mporth.2008.12.005

17. Urbenek T, Ziaja D, Kwiecien A, Wasiak M, Ziaja K. The frequency of thoracic outlet syndrome (TOS) occurrence in a young population between 19-26 years. Chirurgia Polska. 2008;10(1):8-15.

18. Crosby CA, Wehbé MA. Conservative treatment for thoracic outlet syndrome. Hand Clin. 2004;20(1):43-49. PubMed ID: 15005383 doi:10.1016/S0749-0712(03)00081-7

19. Axelrod DA, Proctor MC, Geisser ME, Roth RS, Greenfield LJ. Outcomes after surgery for thoracic outlet syndrome. J Vasc Surg. 2001; 33(6):1220-1225. PubMed ID: 11389421 doi:10.1067/mva.2001.113484

20. Urschel HC. Transaxillary first rib resection for thoracic outlet syndrome. Oper Tech Thorac Cardiovasc Surg. 2005;10(4): 313-317. doi:10.1053/j.optechstcvs.2005.10.002 
21. Povlsen S, Povlsen B. Diagnosing thoracic outlet syndrome: current approaches and future directions. Diagnostics. 2018;8(1):1-11. doi:10.3390/diagnostics8010021

22. Benzon HT, Rodes ME, Chekka K, Malik K, Pearce WH. Scalene muscle injections for neurogenic thoracic outlet syndrome: case series. Pain Pract. 2012;12(1):66-70. PubMed ID: 21635687 doi:10.1111/j.1533-2500.2011.00468.x

23. Lee J, Hwang S, Han S, Han D. Effects of stretching the scalene muscles on slow vital capacity. J Phys Ther Sci. 2016;28(6):18251828. PubMed ID: 27390425 doi:10.1589/jpts.28.1825
24. Greening J, Smart S, Leary R, Hall-Craggs M, O’Higgins P, Lynn B. Reduced movement of median nerve in carpal tunnel during wrist flexion in patients with non-specific arm pain. Lancet. 1999; 354(9174):217-218. PubMed ID: 10421305 doi:10.1016/S01406736(99)02958-X

25. Altug Z. Thoracic outlet syndrome: a differential diagnosis case report. Orthop Pract. 2015;27(2):112-116.

26. Handolescu C, Ispas AT. Ultrasonographic assessment of ulnar nerve dimensions at the level of guyon canal. Rom J Func Clin. 2016; $X V(3): 295-300$ 